\title{
Chapter 5 \\ Managing Irregularity Through the Provision of Public Healthcare
}

Good health is the basis for every human being's autonomy, self-fulfilment and dignity, which is why access to healthcare is generally underpinned by strong individual entitlements and protected through international human rights treaties as well as national constitutions (da Lomba, 2011; MdM, 2014; OHCHR, 2014). The corresponding duty to provide healthcare services to the population has been described as one of the core functions of the welfare state and an important "aspect of modern citizenship" (Aasen et al., 2014, p. 162). Put in Boswell's (2007) terms, healthcare provision thus constitutes one of the 'functional imperatives of the state', whether it is regarded as the fulfilment of a basic and equal right (and thus an issue of fairness) or a necessary measure against potential threats to public health (and thus a question of security).

Any concrete entitlement to access a particular nation-state's healthcare system, however, is underpinned by both a human and a membership right (da Lomba, 2011; Hall \& Perrin, 2015). In many migrant-receiving countries the regulation of healthcare access has thus become increasingly linked to the issue of immigration and its control. By restricting the access of (certain) foreigners on the basis of their immigration status, governments seek to not only prevent so-called 'health tourism' ${ }^{1}$ but also to render a country less attractive as a potential destination for irregular migrants and other unwanted newcomers. Almost unavoidably, such measures also exclude those irregular migrants from effective health screening and treatment who already form part of the resident population, which is problematic from a public health perspective. By the same logic, also the potential inclusion of irregular migrants is not a purely humanitarian issue but reflects their at least partial recognition as de facto members of society. From this perspective, their accessing of such services not only constitutes an 'act of citizenship' (Isin, 2008), but also an act of 'integration' (Schweitzer, 2017). Formal entitlements to even basic care and

\footnotetext{
1 'Health tourism' refers to people who enter another country with the primary intention of receiving a particular treatment that is unavailable or more expensive in their own country of residence.
} 
services can create a sense of inclusion, belonging or even a right to remain in the country of unlawful residence, while serious health issues or the attested need for a particular treatment can strengthen legal claims for regularisation and effectively impede or delay deportation (PICUM, 2009; Kraler, 2011).

This and the subsequent two chapters (dealing with the provision of public education and social assistance) will follow the same structure: After a brief discussion of the underlying contradictions and some of their concrete manifestations in the Spanish and British contexts, I outline the respective legal and policy frameworks within which these various services are provided locally. In a second step, I examine if and how the institutional roles and individual responsibilities assigned to different kinds of actors coincide or conflict with the logic of immigration control. Finally, I employ the analytical framework I developed at the end of Chap. 2 in order to summarise and visualise the findings for each sphere of service provision.

\subsection{Between Hostility and Pragmatism: Ambivalent Legal-Political Contexts for the Provision of Public Healthcare to Irregular Migrants}

Both in the UK and in Spain healthcare is delivered within predominantly tax-based national health systems. These were originally founded - in 1948 and 1986, respectively - on the principles of universal coverage and free and equal access (Aasen et al., 2014), but have recently undergone significant reforms and restructuring (Department of Health, 2010; Legido-Quigley et al., 2013; MdM, 2014). While mainly aiming at increasing overall cost efficiency, these reforms also linked access rules to immigration status and thus allow for, or even require, a more effective internal control of migrant irregularity.

In Spain, the national health reform of $2012^{2}$ categorically excluded irregular migrants - with the exception of emergencies, minor children and pregnant women from free public health care by invalidating the health cards ('Tarjeta Sanitaria Individual', TSI) to which they had been entitled automatically and irrespective of their immigration status once registered as local residents (MdM, 2014). In March 2015, however, the Spanish minister of health announced in an interview that the central government was planning to restore the right of migrants in irregular situations to access primary healthcare services provided within the national health system. This move had become necessary, so the minister, for a number of "practical reasons" such as to "avoid saturating the emergency services" that these persons otherwise tend to fall back on (N.d., 2015). While thus recognising a certain necessity to provide them with some form of access, however, the central government did not foresee irregular migrants' formal re-inclusion into the mainstream system. In fact, the minister was "completely against" making them holders of the TSI,

${ }^{2}$ Enacted through Royal Decree 16/2012, of 20 April, on urgent measures to ensure the sustainability of the national health system and improve the quality and safety of its provisions. 
which "would give them a right that in Europe does not exist in any other country". Instead, they should be given a special type of health card that is valid only within a limited timeframe and specific locality (Rejón, 2015). The restrictive state law remained in force until June 2018, when the Spanish government ultimately re-instated healthcare provision for all migrants, including those in irregular situations (Vosyliute \& Joki, 2018).

Irregular migrants living in the UK, on the other hand, are in principle entitled to access free primary healthcare provided by local family doctors ('General Practitioners', GPs) within the British National Health Service (NHS). Like all other 'Overseas Visitors', ${ }^{3}$ however, they are to be charged the full cost of accessing any secondary (i.e. hospital) care (Department of Health, 2013a, b). This charging regime, first introduced in 2004, has been further extended by the 2014 Immigration Act, which brought significant changes regarding migrants' access to healthcare (Home Office, 2013). One of its main objectives was that "those persons who are here unlawfully should not remain and should have no entitlement to benefits or public services" (Department of Health, 2013b, p. 27). This declared policy goal clearly reflects the UK governments' official strategy of creating, "here in Britain, a really hostile environment for illegal migration", as was first announced by then home secretary Theresa May (cit. in Kirkup \& Winnett, 2012) in May 2012. During the same period, however, there have also been some inclusionary developments in UK, including the extension of healthcare access for irregular migrants in need of HIV/Aids treatment (in 2012) as well as those who can prove to be victims of domestic or sexual violence (in 2015) (Delvino, 2020, p. 89). In November 2013, during a parliamentary debate on the proposed immigration bill and its potential effects on migrants' access to healthcare, then immigration minister Mark Harper also emphasised that the government

[...] will not do anything that will worsen public health. Of course, it is important for those who are in the United Kingdom, even if they are not here legally, to have access to public health treatment, because it has an impact not just on them, but on the rest of the community. ${ }^{4}$

The ministers' statements, both in Britain and Spain, reflect the inherent contradictions between the pressure to restrict the access to these often scarce public resources to 'legitimate' members of the community and the need for pragmatic solutions with respect to those who do reside within a given locality but without the national government's formal consent. In both countries the restrictive reforms have been accompanied by intense debates and critique from health professionals and civil society organisations. Critics frequently highlighted that universal health coverage not only helps preventing the spread of communicable diseases but also plays a critical role for the detection of other societal ills, such as domestic violence

\footnotetext{
${ }^{3}$ The official category used for all foreigners who are not 'ordinarily resident' in the UK, including those holding tourist or visitors' visa, as well as those residing in the country without authorisation. ${ }^{4}$ House of Commons Public Bill Committee: Immigration Bill Deb, 12 November 2013, c310: http: //www.publications.parliament.uk/pa/cm201314/cmpublic/immigration/131112/am/131112s01. htm\#13111257000035 (last accessed 15/12/2017).
} 
and abuse (semFYC, 2012; MdM, 2014). From an economic perspective, it has been argued that early and preventive treatment is cheaper than long intensive care, which often becomes necessary as a result of excluding patients from regular screening and primary care (Aspinall, 2014; Steele et al., 2014; Wind-Cowie \& Wood, 2014; FRA, 2015).

While in both countries the formal responsibility for the provision of healthcare is partly devolved to the regional level, it was only in Spain that the national government's move to restrict the access of irregular migrants has been effectively prevented through legislation enacted by several regional governments. Although it explicitly aimed at a better coordination and overall consistency of service provision, the reform of 2012 thus provoked very different responses across the country, whereby resistance was particularly strong in the Autonomous Communities of Andalucía, Asturias, the Basque Country and Catalonia (DOTW, 2013). Only 4 months after the entry into force of the state law, the government of Catalonia established its own administrative norms according to which irregular migrants explicitly continue to have access to free healthcare provided through the Catalan public health service CatSalut. This conflict is reflected both in political rhetoric and everyday practice and has contributed to a climate of misinformation and confusion among healthcare professionals (MdM, 2014) but also migrants themselves. The following quote from an interview with a Moroccan citizen who spent most of his life in Barcelona but unlike the rest of his family never regularised his situation, reflects this uncertainty:

I have heard that CatSalut said that it would not invalidate irregular migrants' health cards; ... that the Ministry of Health said that they would invalidate them, but Catalonia said no: that it would not implement that. But as I said: right now, I wouldn't be able to tell you. Maybe if I go [my card] wouldn't work, I don't know... (bcnB04).

Also several other respondents explicitly referred to the apparent disagreement between different levels of government when trying to explain the complex and somewhat contradictory rules and procedures of access. A representative of the Catalan Refugee Aid Commission ('Comissió Catalana d'Ajuda al Refugiat', CCAR) put it this way:

Well, that's where you see the clash: it's the central government that wants to limit the services and attention to immigrants in irregular situations, whereas I think at the [lower] levels - for example in the municipality of Barcelona - they are more aware [of the social consequences] (bcnA04).

Also in the UK context, the Greater London Authority (GLA) - which has no formal competence in the area of health - has occasionally taken a more pragmatic position than the national government. A senior advisor to former mayor Boris Johnson told me in an informal conversation that when talking about health issues internally, such as the need to raise awareness about Tuberculosis, "we obviously don't exclude irregular migrants, but we also don't explicitly include them" (lonC04). Already in January 2012, as part of the Mayor's Integration Strategy, the GLA had published a pamphlet available in 20 languages to make migrants and asylum seekers aware of their entitlement to register with a GP. A representative of 
the London-based Migrants'Rights Network (MRN), which collaborated with the Mayor's Office on this issue, recalls that

\begin{abstract}
there was a big concern among the London authorities, [in spite of] what the national government was saying, [...] that not enough migrants, including undocumented migrants, were going to see a GP or where in touch with the health authorities when they should be, especially pregnant women. So, they were taking some steps to actually encourage people to access the health system (lonA02).
\end{abstract}

The leaflet particularly emphasises that applicants are not legally required "to prove their identity or immigration status to register with a practice" and that GPs cannot refuse registration on discriminatory grounds. The campaign was a reaction to the frequent misinterpretation of existing norms regarding (particularly irregular) migrants' access to NHS services, and has been heavily criticised by right-wing pressure groups for further encouraging 'health-tourism' (Johnson, 2012). Around the same time, and more in line with this criticism, an official poster campaign in NHS facilities specifically reminded those "visiting the UK, or not living here on a lawful and settled basis" that they "may have to pay" for their healthcare. As shown in Fig. 5.1, some of the posters clearly emphasised that access to public healthcare is closely linked to immigration (status) and that NHS staff can play a role in controlling both. From the perspective of irregular migrants, such information is likely to further increase uncertainty or even fear of being detected and apprehended as a result of accessing these services.

These examples suggest that not only (irregular) migrants themselves but also the public employees who administer or provide healthcare services to the population
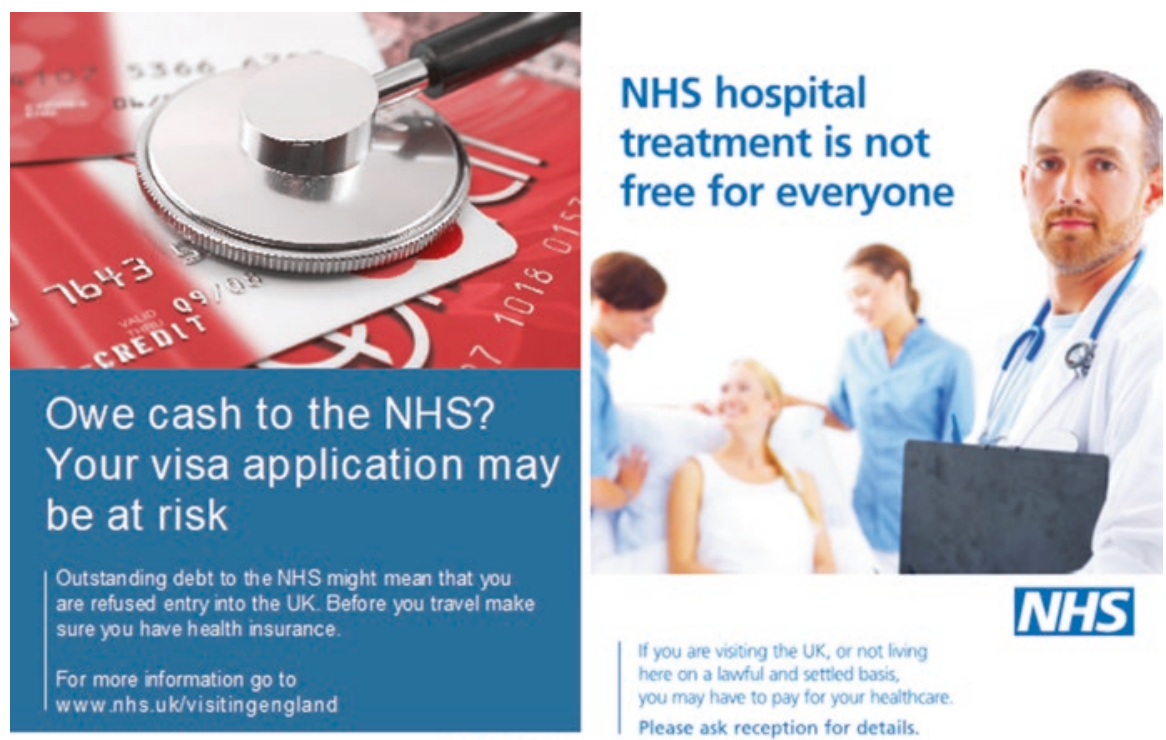

If you are visiting the UK, or not living

here on a lawtul and settled basis,

you may have to pay for your healthcare

Please ask reception for details.

W/AS

Fig. 5.1 NHS poster campaign - 'Healthcare is not free for everyone' 
are exposed to contradictory signals and information regarding the relevance that a patient's immigration status should have for them. In the remainder of this chapter, I will focus on the roles and perspectives of different kinds of healthcare workers as well as the legal and institutional structures in which their actions and decisions are - more or less firmly - embedded. What interests me in particular are the different ways and varying degrees to which they thereby become implicated in immigration control.

\subsection{Legal Frameworks, Formal Entitlements and Practical Barriers for Irregular Migrants' Access to Public Healthcare in London and Barcelona}

For analytical purposes it makes sense to differentiate between primary and secondary care even though in practice, they are closely linked through internal referral systems and one cannot fulfil its function without the other. Since access to the latter usually implies much higher costs to the healthcare system it tends to be subjected to tighter access rules and stricter controls, which is why I discuss them separately.

\subsubsection{Irregular Migrants'Access to Primary and Emergency Healthcare}

According to the respective legal frameworks, third-country nationals residing unlawfully in either London or Barcelona are formally entitled to access free primary healthcare services provided at local health centres, as well as Accident and Emergency care (A\&E). In both contexts, the right to receive primary care is based on the recognition of a patient's residence within a particular area, which he or she has to prove by providing more or less specific documentation. In Spain this is generally done through the obligatory inscription in the municipal register, which constitutes the primary requirement for all residents to benefit from any public service provided at the local level (see Sect. 4.2). A senior official of CatSalut put it this way:

The issue of [municipal] registration is a way, I think, also to formalise the residence; it is to say: 'You are entitled to the provision of health services because you form part of the population of this territory' (bcnA17). 
In contrast to other parts of Spain, irregular migrants who have been registered in Catalonia for at least 3 months ${ }^{5}$ and earn less than the official minimum income ('Renta Mínima de Inserción', RMI) can apply for a health card, which gives access (for 1 year, after which it can be renewed) to free primary care, any urgent treatment, as well as health programmes 'in the interest of public health' such as HIV/ Aids screening and most vaccinations. In principle, applications are made directly at the local health centre ('Centro de Atención Primaria', CAP), where applicants have to produce a document obtained from the National Institute of Social Security (INSS) certifying that they are not covered under the national system, an official confirmation of their municipal registration, and a copy of their valid passport or other ID (Ajuntament de Barcelona, 2013). Only where insufficient documentation inhibits this formal procedure, applications have to be processed through NGOs like the Red Cross.

In the UK in contrast, where no general system of residential registration is in place, anybody who wants to register with a GP has to provide other "proof of address', usually a utility bill or bank statement in the name of the applicant (see Sect. 4.2). While all GP practices are obliged to provide emergency and immediately necessary treatment to any person within the practice area, they can exercise some degree of discretion about whether or not to register a person; or to treat them privately, that is, as self-paying patients (da Lomba, 2011). Importantly, and other than in Catalonia, there is no specific legislation regulating the provision of primary care to 'overseas visitors' and no required minimum period of residence, so that even persons staying in the country for less than 3 months might be included in the regular patients list or be registered as 'temporary residents' (Department of Health, 2012). GPs can only refuse a patient on reasonable, non-discriminatory grounds for example because they live outside the catchment $\operatorname{area}^{6}-$ or if their list is full (Aspinall, 2014; Wind-Cowie \& Wood, 2014). Even regarding the widespread practice of requiring a personal ID at registration, the British Medical Association (BMA, 2013) advises practice staff that "[o]verseas visitors have no formal obligation to prove their identity or immigration status to register with a practice". In spite of this, as Doctors of the World (DOTW, 2013) have denounced, over two thirds of London's Primary Care Trusts have issued guidance that is incompatible with GPs' legal obligations; for example, by advising them to only register people who live in the UK lawfully and for more than 6 months. While according to the law this 'ordinary residence' criterion only applies to secondary care provision, it is sometimes (falsely) extended to primary care, as the account of one GP I interviewed in South-East London reveals:

\footnotetext{
${ }^{5}$ Notably, this temporal limitation is being justified as a necessary measure against (mostly European) 'health-tourism', rather than preventing irregular residents from accessing these services.

${ }^{6}$ Since 5 January 2015, GP practices in England are also free to register new patients who live outside their practice boundary area, which means that they don't necessarily have to ask for proof of address, see: http://www.nhs.uk/nhsengland/aboutnhsservices/doctors/pages/patient-choice-gppractices.aspx (last accessed 15/12/2017).
} 
It's true that we have a very good system that is free at the point of delivery, but you still have to have an NHS number. That means that you would need to be a resident in the UK for at least 6 months in a year. [...] If, for example, you are visiting for a short time, you do have to pay even to see a GP. [...] So... I mean, sometimes we do try and help as much as possible, $[\ldots]$ but it depends, of course. It's different from one doctor to another, from one surgery to another, even in primary care (lonA25).

The Department of Health (2012, p. 9) already acknowledged that in contradiction to current regulations "some [GP] practices have deregistered or failed to register people they believe to be 'ineligible' in some way due to their immigration status". As a result of the inconsistencies between formal entitlements and everyday practice, even migrants who try to register with the support of specialised NGOs are often ambiguously refused. A study based on evidence and experiences gathered by Doctors of the World concludes that " $[\mathrm{t}]$ he biggest barrier to GP registration is the inability to provide paperwork", in most cases a valid ID and/or proof of address (DOTW, 2016, p. 9). According to the organisation's programme director for the UK, these are

barriers that are put in place by the system, which are sometimes deliberate and sometimes not deliberate. [... As] an undocumented migrant it is very likely that you won't have a valid passport or utility bills in your name and lots of practices are very rigid in terms of how they apply these rules, [so] the system doesn't recognise that people may not be able to provide those proofs and that is actually a true barrier to care, which means they cannot access any healthcare (lonA03).

In practice, many migrants in irregular (or legally ambiguous) situations thus remain effectively excluded even from the most basic provisions. Such informal exclusion can be the result of administrative barriers, a lack of awareness of their entitlement, or fear of being reported and thus potentially detained or deported as a result of approaching a public health service (OHCHR, 2014). Especially the latter seems to be a bigger issue in London than Barcelona, and particularly among those migrants who never had a residence permit and are not in contact with any support organisation that would provide them with the necessary information. This was the situation of a young man from Albania who I interviewed in South-London, where he had been living for almost 2 years:

It's difficult man. It's really difficult because if you have any problems, [...] like if you get sick or something like that, you don't have any place to go, you don't have anyone to care about you. It's difficult. [...] I never even tried [to register with a GP] because I know how it works here, you know. They will ask you for an ID and I don't have... I mean I have, but only my Albanian ID and that is not valid for this country (lonB03).

He was clearly unaware of the fact that even though his Albanian passport is not valid as proof of legal residence in the country, it is still a valid form of identification within all those institutional settings where entitlements and access are not linked to immigration status. Another Albanian citizen who had spent almost 15 years living and working in the UK also told me that he usually relies on self-diagnosis or private healthcare providers, even though he feels he should be entitled to access public services since he is paying into the system: 
I do work hard, and I pay my taxes to the government and all that, but I don't have the right to go to the doctor. I don't have a GP, so normally I go to private health[care]... which as you probably know costs thousands! [...] So far, I have been trying to find things online, [...] if I don't feel well, I read things online, trying to find out what's wrong with me and just go and get the medication from a pharmacy or somewhere... And if I really have to go to a doctor, I have to do it privately. For example, I had to have them remove my tooth, last year, which cost me 1500 pounds. [...] You just go, and they treat you. They swipe the [credit] card, and if you have money in your bank, they treat you well [laughs]

[Interviewer] ...but they don't ask anything else?

No, they don't ask anything. Only 250 pounds; that's only for the appointment, only! And then they charged me 1.225 for removing the tooth, which took them less than an hour, right? But I had to do it, because I was in pain.

[Interviewer] So you have never even tried to register with a GP?

No, because you can't register with a normal GP. I haven't even tried that myself, because if you do, you get asked questions and all that, and someone [from the Home Office] might be there as well, and so... it ends up there. Even though I am paying taxes, yeah? (lonB08).

Such accounts explain why almost $90 \%$ of over 1.500 patients who were received during 2012 at an independent health clinic run by Doctors of the World in EastLondon were not registered with a GP (DOTW, 2013). A representative of the organisation told me that when they

ask people for the reasons why they haven't been to the [regular] health service [...], like one in five say they think they will be arrested if they go and see a doctor; and we see people with symptoms that are potentially serious or infectious diseases, who are not presenting to health services for precisely that reason (lonA03).

Given the significantly less 'hostile' environment that irregular migrants generally face in Spain and particularly in Catalonia, as I argued in Chap. 4, it is no surprise that fear of apprehension represents much less of a barrier in Barcelona. A qualitative study carried out by the city's Public Health Agency (Agència de Salut Pública de Barcelona, 2011), found no significant difference in terms of the selfreported experiences of trying to access healthcare between migrants in regular and irregular situations. The Platform for Universal Health Care in Catalonia (PASUCAT, 2014), an umbrella group of health professionals and NGOs dedicated to documenting the "often arbitrary application of the new health regulations in Catalonia", found 72 cases of arbitrary exclusion of migrants over a period of 2 years. More than half (54\%) of them were lawful residents, which equally suggests that irregularity as such does not constitute a significant barrier. All the irregular migrants I interviewed and most of those I informally spoke to in Barcelona had eventually managed to get a health card, although many of them have been assisted or at least received guidance by local NGOs. Interestingly, the only interviewee who told me that he and his family "had a lot of trouble getting integrated into the system" was a 28-year-old US-citizen who also mentioned that he usually has no difficulty "passing as an American tourist" (bcnB03). In this case, the intersection of immigration status with racial privilege, which I briefly discussed in Sect. 2.2, works in a contradictory way: While it does protect my interviewee from being stopped by the police (see also Romero, 2008; Cebulko, 2018), it effectively 
weakens his position vis-à-vis the healthcare system, for which he appears as a 'health tourist' (from a wealthy country) and as such, as undeserving of public support.

The relatively complex procedure established by the Catalan government requires all applicants to approach various public institutions in order to activate their formal entitlements. This premises not only substantial knowledge of the registration process, official language and institutional setting, but also a significant degree of trust in 'the system', which migrants in irregular situations all too often lack. The following account of the same interviewee illustrates that in spite of his relatively privileged position - as a white Westerner with a fairly stable job and university degree in translation - the irregularity of his stay renders such encounters with 'the state' a potentially risky endeavour and often requires careful differentiation between various kinds and levels of authority:

Overall, I trust the offices of the municipality, [but] I am really nervous about going to Social Security. But I have to in order to do some of the stuff that I am going to do, like in order to get health coverage I think I have to go to Social Security and get a letter saying that I don't have the right to Social Security [laughs] [...] It's sort of like, if I were working somewhere illegally, those are the people that would come and inspect me and then report me, you know. And so, sort of going willingly and saying to them 'Hi, I don't have any right to be here, please give me a right to use your [healthcare]' [laughs] ... it's so contradictory! So that makes me nervous, but people do it. That's what you are supposed to do. So, if that's what you are supposed to do, I'll do it, but it makes me nervous (bcnB03).

The fact that at least he knew what he was supposed to do reflects one of the major differences between the two environments I am comparing: While in both contexts access rules to free primary healthcare formally include (or at least do not exclude) irregular migrants, only in Catalonia is this entitlement reflected by an explicit legal framework and a specific administrative procedure. Both require and reflect a political decision through which politicians formally justify the inclusion of these local residents as necessary. This arguably also reduces the pressure on individual providers and administrators of care, as the following accounts of a receptionist (1) and a family doctor (2) of a CAP in Ciutat Vella suggest:

(1) It is simpler for us [to register a person with regular papers] because it is very automatic and easier to introduce them [into the system]. But well, now that we have this type of health card [for persons in irregular situations] - which we didn't have before - also in their case, once they fulfil the requirements, we automatically put them on, we assign them a doctor, give them appointments, and so on (bcnA13).

(2) Look, for me they simply appear on the list of patients that I am going to see on that day, whether in a regular consultation or as an urgent case [...] So this patient, who in principle is in an irregular situation, appears on my list, and I don't question anything (bcnA12).

In the UK in contrast, irregular migrants accessing NHS care always constitute "an exception to the rule that makes eligibility contingent on lawful residence" (da Lomba, 2011, p. 363). In the words of two London-based health advocates $(1,2)$ and a GP I interviewed in Hackney (3), this means that.

(1) there isn't a system here that you have to go through and get a certificate from somewhere which you then take to the hospital. So, either you are in, and anybody can be in, or 
you are not in. But there is confusion about who is in and who is not in, and that's the difficulty (lonA08).

(2) It is not widely understood or accepted that undocumented migrants should have access to these services, even though in law there is nothing that says that they shouldn't. There is not a positive acceptance that this is our position and so that means that quite frequently health staff mistakenly turns people away because they think they are not eligible (lonA03).

(3) I get the feeling that undocumented migrants [...] do not have the backing of the law. The law is made vague so that it's very difficult for them to weave their way through it (lonA11).

As I will show in the following sections of this chapter, the legal but also moralpolitical ambiguities that always underlie the provision of healthcare to irregular migrants create difficulties not just for service users but also the very institutions and individual professionals providing or administering these services. Some of the differences in how these dilemmas are dealt with in London and Barcelona, respectively, become more pronounced when extending this comparison to the level of secondary healthcare.

\subsubsection{Irregular Migrants' Access to Secondary Healthcare}

According to the legal framework established in Catalonia in 2012, migrants in irregular situations were initially only given normalised access to secondary care after a continuous residence of 1 year. In case they requested or needed any hospital treatment before fulfilling this requirement, it had to be authorised on a case-bycase basis by a special commission within CatSalut, which had specifically been set up in order to deal with this situation. While Medicos del Mundo (MdM, 2014) criticised the absence of transparent criteria to be applied by the commission in determining each individual case, several of my respondents working within CatSalut perceived the whole procedure as mainly creating additional work as well as unnecessary delays to treatment, rather than a way of ensuring the effectiveness or sustainability of the healthcare system (bcnA17, bcnA08). I will discuss the role of this commission in more detail in Sect. 5.3, but what is important to note here is that following significant pressure from professional associations such as PASUCAT, the government eventually abandoned the 1-year waiting period in July 2015. Since then, irregular migrants have access to the full range of publicly funded services after only 3 months of (officially documented) residence in Catalonia (Blay, 2015).

Recent developments in the UK, on the contrary, point in the opposite direction: Since 2004, when the government first introduced the Overseas Visitors Hospital Charging Regulations, all foreigners who are not 'ordinarily resident' - a status not explicitly defined in law but conditional, among other things, on lawful residence are categorised as 'Overseas Visitors' and as such, in principle, should be charged 
the full cost of any NHS hospital treatment they incur ${ }^{7}$ (da Lomba, 2011; Department of Health, 2013a; Aspinall, 2014). At the same time, however, the Department of Health (2013b, p. 55) also makes very clear that where treatment is considered 'urgent' or 'immediately necessary' it cannot "be delayed or withheld pending payment", which again gives significant weight to the medical assessment of the patient's condition. As I will discuss in more detail below, the discretion in taking these decisions comes with the very nature of the medical profession and thus unavoidably plays a significant role within every healthcare system (semFYC, 2012). In the case of the UK, however, treatment of 'Overseas Visitors' is officially defined as 'urgent' where it "cannot wait until the person can be reasonably expected to return" to their country of citizenship (Department of Health, 2013a, p. 43). Clinicians are thus automatically required to take into consideration the likelihood and possible duration of a patient's stay in the UK (da Lomba, 2011). Both directly depend on his or her immigration status and are particularly difficult to assess in the case of irregular migrants, who are estimated to represent more than $60 \%$ of the total 'chargeable population' (Department of Health, 2012, 2013a).

On one hand, the fear of having to pay - or even to receive a bill later on - obviously constitutes a significant additional barrier for many migrants in economically unstable situations. Being poor, thereby increases the exclusionary effect of irregularity. On the other hand, this is also where the incentive for NHS hospitals to recover the costs of the services they have delivered starts to overlap with the efforts of immigration authorities to detect irregular residents or at least deter their use of public services. According to current rules, once identified as an 'Overseas Visitor', the full costs have to be borne by the patient, or otherwise - if they cannot pay - the individual hospital. While this is meant to encourage hospitals to require payment in advance or otherwise deny treatment (where it is not considered 'urgent' enough), an official review of this policy recognised a lack of incentive to properly identify chargeable patients in the first place (Department of Health, 2012). While the efficiency of this system thus hinges on the participation of individuals working within each hospital, the structural proximity between healthcare and immigration policy also becomes explicit through a formal mechanism that allows

NHS bodies [... to] share non-medical information with the Home Office, via the Department of Health, on those [patients] with a debt of $£ 1,000$ or more once that debt has been outstanding for three months, with a view to better collect debts owed. The Home Office can then use that information to deny any future immigration application to enter or remain in the UK that the person with the debt might make (Department of Health, 2013a, p. 63).

While the threshold has since then been lowered to $£ 500$, this information exchange does not require patients' explicit consent although they "should" be made "aware of the potential immigration consequences of not paying" (ibid.). For

\footnotetext{
${ }^{7}$ Until 2004, like in Catalonia between 2012 and 2015, they were entitled to free treatment after 12 months of, even irregular, residence in the country. Exceptions from the general charging regulations are in place for certain cases, such as the diagnosis and treatment of a regularly updated list of communicable diseases.
} 
Max Wind-Cowie and Claudia Wood (2014, p. 13), this "poses an enormous ethical challenge for healthcare professionals and the NHS as a whole". A maternity health advocate I interviewed in Hackney described this dilemma from the perspective of a midwife:

Should she say, 'I will treat you because you are entitled to maternity care, but I have to tell you that you will be billed, and if you can't pay the bill, that information will be sent to the Home Office'? I mean, I don't know what I would do if I was a midwife, but that would be the correct information (lonA08).

In this context, Rayah Feldman (Feldman, 2020) argues that the NHS charging regulations as such effectively discriminate against (migrant) women in particular, whereby she highlights the intersectionality of immigration status on one, and gender on the other hand.

The existence of such mechanism together with media reports about the Home Office routinely "accessing NHS records to help track down illegal immigrants" (Ball, 2014), strikingly highlight the lack of what numerous human rights bodies and NGOs describe as a necessary firewall between the state's health services and its immigration enforcement agencies (FRA, 2013; OHCHR, 2014; Hermansson et al., 2020). DOTW specifically criticised the NHS Health and Social Care Information Centre, which collects data about everyone accessing NHS health or social care, for sharing personal information of individual patients - including the locality where they are registered with a GP - with the Home Office in response to so-called 'trace requests'. According to a representative of DOTW, this "is the first time that we see that despite reassurances [by the Department of Health] actually information is being shared by health services for the purpose of immigration enforcement, and we are really worried about that" (lonA03).

In several respects this stands in stark contrast to the situation in Catalonia: Firstly (and this is the case in all of Spain), the unconditional entitlement of all minor children and pregnant women to free healthcare is safeguarded under national law and was left untouched by the restrictive health reform of 2012. Secondly, whether or not foreign patients are to be charged for the services they receive from CatSalut depends on whether or not they are residents of Catalonia and whether or not they have the economic means (or insurance) to pay, but not on the 'legality' of their presence. In practice, migrants in irregular situations and without resources might still be issued a bill and even the fear or expectation thereof can in some cases pose a barrier, as a community health worker told me from her experience at one of Barcelona's biggest public hospitals (bcnA10). What these patients are often not aware of, however, is that receiving a bill will remain without further consequences for their (irregular) stay in the country, as CatSalut's client relations manager clarified in an interview:

This could happen in some cases, mostly because [...] it is difficult to identify in a hospital [whether someone is a tourist and thus has to pay or have a European health card; or an irregular resident without resources], and so they sometimes make a provisional invoice ('pre-factura'). But what is clear here is that we don't pass these provisional invoices on they don't become official debt - and if the patients tell us, or they tell the hospital rather, 
that they don't have resources, these invoices are cancelled, and the costs will be assumed by CatSalut (bcnA17).

Thirdly, and related to the latter, many of the health advocates, professionals and NGO workers I interviewed in Barcelona made very clear that public services play no active role in immigration control, let alone enforcement (bcnA02, bcnA10, bcnA12, bcnA13). That said, however, it is also important to differentiate between the function(s) of public institutions and the behaviour of individual street-level bureaucrats working within them, as a representative of Caritas Barcelona specifically pointed out to me:

It is true that going to social services or to the doctor you can find racist people, or people who are against immigrants, and so a migrant can be [treated wrongly]. But this is an individual issue $[\ldots]$ it is not that the educational or sanitary institutions, or social services, would carry out controls for the police, or for the ministry of the interior, no. It doesn't exist and nobody would defend that or say that it should exist (bcnA03).

Partly in order to bridge the conceptual gap between individual and institutional practices, the focus of my subsequent analysis is at the level of 'organisational roles', i.e. the particular positions and corresponding functions that individuals occupy within certain institutional settings (Lipsky, 1987; Scott, 2001; Webb, 2006). In the remainder of this chapter, I will look for instances where the professional or administrative duties attached to these roles are affected by the intersection of two functional imperatives of the state: the provision of healthcare and the control of immigration.

\subsection{Negotiating the Effective Limits of Access, Medical Urgency and Immigration Control: The Role(s) and Agency of Healthcare Workers}

As discussed in Sect. 3.1, my analysis differentiates between the roles and functions of three broader categories of actors: (i) general administrative personal, (ii) professional service providers, and (iii) those actors more specifically responsible for managing migrant irregularity within a certain sphere of the public welfare system. This will allow for a systematic comparison of their varying degrees of power, discretion and involvement with immigration control and enforcement across different sectors of service provision.

\subsubsection{Administrators of Healthcare}

Whether in a hospital, health centre or GP practice, most service users' first encounter with the public healthcare system is through reception staff, who are usually responsible for providing information, registering new patients, assigning them to a 
doctor and arranging their appointments or referrals to other services. The main focus here is on patient registration, whereby they implement the formal access rules outlined earlier and thus apply the criteria established through laws and regulations. The receptionist of a health centre in the Raval, the multicultural heart of Barcelona, put it this way:

They [the politicians] are the ones telling us how we must work, in principle, no? This is to say: the system functions a bit according to what they tell us. But OK, then we know for ourselves how we can mould it ['moldearlo']. We are part of this as well, but...of course, sometimes they put us a lot of obstacles, so we are unable to do our best possible work, no? Sometimes we would like to do more but it's not possible because they don't let us (bcnA13).

Even though the formal rules and limitations to individual agency are the same for all practices within a certain territory, the outcomes of these negotiations can vary significantly. The experience of a social assistant working for the Catalan Refugee Aid Commission in Barcelona confirms this:

What we have detected a lot here is that it depends on the CAP $[\ldots]$ and it depends on the person. That's it. It depends on the person that happens to be at the counter and that is more or less sensitive to these issues... you know? It depends on the will [of that person], that's how it is. But the legislation is this, at the moment (bcnA04).

It is not surprising, then, that even in Catalonia where the rules are clearer and tend to be communicated more openly and proactively than in the British context, many migrants at least initially struggle to gather the correct information, as one of my interviewees remembers:

[D]ealing with the health system is one of those things where you go into an office and every time they tell you something different, or every person tells you something different. [...] So basically, it's a question of... I need to probably go to a different [health centre where nobody remembers him] and lie. And say, 'I'm a student but my visa has lapsed, and I am here irregularly, I don't have the money for insurance, bla bla bla... please!' And then cross my fingers and hope that I found the right person (bcnB03).

This account also reflects a strong awareness of the fact that finding the right person can make a significant difference. At the same time, however, individual attitudes and responses to irregular migrants and their claims also have to be understood within their legal-political as well as institutional context. For example, several of the people I interviewed in London directly related the less favourable attitudes they were experiencing on the part of some healthcare workers to the central government's 'hostile environment' policy or rhetoric. A caseworker for DOTW put it this way:

Some of them are perfectly nice and want to help and do understand that people are in a difficult situation and just need healthcare; but others, truly, are feeling that by refusing to register an irregular migrant they are protecting their country and they see themselves as part of the Home Office by checking immigration statuses, which is not their job. But, yeah, I think that it's more about the general climate that was created over the past few years (lonA12).

This 'climate' thus seems to be conducive to what I introduced (in Chap. 2) as autonomisation, and some welfare workers might thereby even feel encouraged to 
at least try to find out the immigration status of the people requesting a service. At the same time, and this is the case in both cities, also the health centre management has a certain degree of both formal and informal discretion about how strictly the rules are to be applied in everyday practice. At least in Barcelona this administrative room for manoeuvre is often used with the aim of including patients who are in irregular or semi-irregular situations. This was most apparent with respect to those who do not (yet) fulfil the 3-months-residence requirement and are thus categorised as potential 'health tourists'. One receptionist told me that in the CAP where she works,

[...] they have even given us informal orders to be able to attend to this type of person, [...because] if we were to comply with the regulations, we would have to charge them for their visit. But this for example... we just don't do it ['lo pasamos'] (bcnA13).

According to the same interviewee, the rules tend to be applied more strictly in other parts of Barcelona where immigration and irregularity are less common, so that administrative personal themselves have to find ways to "make exceptions" where to them it seems necessary or simply convenient. For example, they can provisionally arrange a first appointment with reference to some "pending documentation" that the patient "is still in the process" of obtaining (bcnA13), or - as another administrator told me - by recording the appointment under a slightly later date so that it falls within the period of the patient's formal entitlement (bcnA08). Interestingly, the second interviewee also mentioned that when migrants try to register a family member (usually a child) who is not present in person, "I always tell them: 'no, you will need to bring your child, because I don't know if your child is still in your country"' (bcnA08). Both instances can be seen as strategies employed by individuals - the receptionist in one case and the child's parent in the other - to circumvent the same temporary limitation imposed by law in order to more strictly regulate access to the Catalan healthcare system.

In this sense, the situation is not too different from that in London, where at least some GP practices are aware that a too rigorous interpretation of official access rules might infringe their legal obligations towards local residents and thus opted for an explicitly lenient interpretation of these rules. When I asked the head receptionist of a GP surgery in Hackney what kind of documentation she and her team would usually ask for, she was keen to emphasise that

here we don't take anything - no more. We used to ask for proof of address, but for the last 3 or 4 months we were told [that] we are not allowed to require any proof of address. So, if someone says, 'I live there', that's it. If it's in the catchment area, we just allow them to register without any proof [...]. We don't ask for any kind of proof, ID, or anything like that (lonA14).

From her own perspective as reception staff, however, she also recognised that what she described as "our doctors' decision" - to not (anymore) verify the patients' home address or even identity - does create more work for her and can make it more difficult to administer any continuous or follow-up treatment:

I am not saying that we should [ask for proof of address] but it also helps it to be easier. At least we wouldn't have a lot of people registering at one address and then when the health 
authority sends out their medical card, it comes back as 'not known'. Because that also means that it's a lot more work this way, but it's not my decision so I don't really... I just go along with it. [...] I also think that a lot of other surgeries ask for proof of ID just to make sure that the patients are who they say they are and that they are registered correctly, because [here] you can come and change your name the next day and say I am someone else. So [...] how do you know that the care that you are giving is actually for that particular person? So, this is where I would find it a little bit conflicting, but as I said, it's not my decision (lonA14).

Quite clearly, it is mostly the administration of public healthcare - rather than its actual provision by doctors and nurses - that is rendered more complicated by a lack of official documentation. This has also been noted by respondents in Barcelona, where minor children, for example, are entitled on the sole basis of their age and independent of the place, length or 'legality' of their residence. Asked how a patient's age is assessed in case no documentation is presented, the reception manager of one CAP said:

I just believe it. When I am in doubt I just believe [them]. Also because, let's say, they have the face... OK, someone who is 20 can fool me and say s/he is 18 . But there are not so many, you know, if that happens once, in one year, it will not affect us very much. Now, if that would happen a lot, then some kind of control would be needed (bonA08).

Importantly, given the nature of official identification documents such as the passport, it is only a small step from verifying a patient's identity or age to (also) checking their immigration status. A recent report by DOTW (2016) shows that $13 \%$ of the recorded refusals of GP registration in England were due to reception staff mistakenly requiring proof of legal immigration status, which the applicants were unable to provide. In each of these cases, a health centre receptionist had felt entitled to or even responsible for exercising internal immigration control. Neither in the UK nor in Catalonia does the receptionist's role involve a duty to systematically check immigration statuses, but it was mostly in the latter context that those I interviewed questioned their own authority to do so, as one of them emphasised:

Well, sometimes when I ask for their documentation, they tell me they don't have [any], and so, of course, you'll have to believe it. I cannot force anyone to show me [a passport]. If s/ he tells you that s/he doesn't have one, you believe it. And then later it sometimes comes out that s/he actually has a passport; that also happens. But I cannot refuse [registration] by demanding that they show me something (bcnA15).

At the same time, and in both cities, some of the reception staff I interviewed were convinced that being 'laxer' or having 'more open' access policies than other practices within the same area would automatically divert people - and particularly those perceived as administratively 'difficult cases' - to them, as the head receptionist I interviewed in Hackney pointed out:

I don't know why [the other practices] have made those kinds of decisions, but what I am saying is [that] because we stick out, people will come here more, because we don't ask for proof of address. So, a lot of our services will probably get overloaded; because... sometimes it goes through word of mouth, so someone would say 'hey, you don't need to provide proof of address here, just say you live here' (lonA14). 
This clearly echoes a familiar argument about immigration that is almost as widely accepted as it is difficult to substantiate or quantify: that comparatively liberal access policies but also stronger protection or better visibility of existing rights and entitlements granted to foreign residents will automatically attract further 'unwanted' immigration. As Marlou Schrover and Willem Schinkel (2013, p. 1130) put it, "no country wants to be accused of being less humanitarian than neighbouring countries, but no country wants to attract migrants with too much humanitarianism either". Both at the level of states and that of health centres, this so-called 'pull-effect' is often suspected of leading to some kind of 'overload', unless it is countered through effective gatekeeping mechanisms.

Within the health centre, a lot of the gatekeeping responsibility is borne by frontline staff. The above-cited report on GP registration in England specifically highlights that in $32 \%$ of all refusals the responsible practice manager was not available to confirm the receptionists' decision (DOTW, 2016). The latter thereby informally exercise a kind of discretion that is not explicitly foreseen under the current legal framework, although it arguably is fostered by its ambiguity. Here it is important to note, however, that individual gatekeepers can also use their discretion to facilitate access to a service they administer, as becomes clear from the following account of a reception manager I interviewed in the district Sant Martí of Barcelona:

\footnotetext{
When $I$ refer someone [to secondary care] and tell [the hospital] that $\mathrm{s} / \mathrm{he}$ is an irregular migrant who does not have anything [no money] ... then the hospital will charge it to CatSalut. Now, if the person arrives at a hospital and has not passed through me, they're going to give him/her a bill. [...] They always have to go through primary care, because $I$ am the one who sends them. So, if I send them, they will not be billed, and everything will be processed via CatSalut (bcnA08).
}

Independent of whether it bars or facilitates someone's access to something, gatekeeping always involves the exercise of a certain from of power that comes with a particular role. While the power and responsibility to refer someone (or not) to a hospital actually lies with the family doctor - rather than the receptionist - it is important to remember that both in the UK and in Spain all patients (including citizens) are subject to this very kind of gatekeeping: If they want to receive a specialised treatment or examination that is publicly funded, they have to go through primary care and be assessed by their family doctor or GP as being in need of such service.

Throughout this book I argue that gatekeeping and other practices of inclusion or exclusion can only constitute a legitimate exercise of power or discretion as long as they are based on the internal logic(s) of the very subsystem which in order to effectively fulfil its function for society requires this particular power to be vested in a particular role. As soon as receptionists or other healthcare workers (have to) follow or take into account the external logic of immigration control when exercising their power or discretion over a patient, they become deputies of the immigration regime. The same is also true for medical professionals whose role and responsibility towards their patients is, overall, more likely to conflict with the logic of immigration control. 


\title{
5.3.2 Professional Providers of Healthcare
}

When talking about irregular migrants' access to healthcare, many of my interviewees in both cities referred to the moral obligations and professional values attached to being a doctor or nurse. Quite often they pointed at the tension, if not outright contradiction, between these values and duties on one hand, and immigration law and the corresponding administrative procedures on the other. Especially healthcare professionals themselves were very often concerned about instances or mechanisms of selective exclusion towards certain groups of people from the services that, after all, they provide. A family doctor working in Ciutat Vella (Barcelona) put it this way:

\begin{abstract}
We have our own deontological code [...which] is necessary to ensure good practice and the well-functioning of [the healthcare system], right? So, we cannot distinguish people by religion, and just as we don't deny health services to a person who is of a particular religion, also a particular administrative situation [...] would not be a cause [for exclusion]. We are very aware of this, but obviously the government's policies are often antagonistic... contrary to our deontological code. And so, we enter in a kind of moral conflict, or they intend that we enter into a moral conflict - into which we do not really enter because [for us] it's life above all else, taking care of and helping [the patient] above all else (bcnA12).
\end{abstract}

On the basis of these principles in combination with a particular expertise and bolstered by a strong professional standing within society, their job gives them a significant amount of individual discretion. This is most obvious where health professionals are expected to decide whether a particular case constitutes an 'emergency' and which types of care should be considered as 'necessary' (DOTW, 2013; OHCHR, 2014). The responsible doctor of another CAP in the centre of Barcelona proudly maintained that the ambiguity of these concepts together with the legal protections they afford allows him to basically treat anyone without breaking the law:

We [doctors] can decide that, and that opens a door for us to make different exceptions when we think it is appropriate from a medical point of view. [...] According to the law you can treat any urgent [case], someone that you consider is an urgent case. And I can consider that everything that comes through the door is an urgent case (bcnA14).

That said, he also acknowledged that depending on the workplace and specific role within the healthcare system, certain administrative rules and requirements more or less easily get in the way of doctors' professional freedom. ${ }^{8}$ While he generally appreciated that "under the law that they made in Catalonia you can sort out most [cases] pretty well" (bcnA14), he also noted that the recent introduction of a computerised system for prescribing medication has limited the flexibility that he used to have when writing all prescriptions by hand.

At the same time, the accounts of health professionals I interviewed in Barcelona and London also reflected their awareness of the fact that public funds are limited, and their decisions as public servants thus need to be justified. As one doctor in

\footnotetext{
${ }^{8}$ For example, family doctors will encounter different barriers in their everyday dealings with their patients than doctors working in A\&E.
} 
Barcelona put it, this usually involves weighing the costs of a particular treatment against its perceived necessity:

[It depends on] the cost that it represents [to the healthcare system] and even if we suppose that I see [one additional patient] each day - which is not even the case - they will still pay me the same, and so it will not be felt by the administration [...] or by society. [It will make a difference] just for me, but not beyond. So, I am not sure... but of course the funds are limited and come from everyone [...] and so I think that it would need a solution that involves the whole society and not just one professional. But in any case, I have to say that I don't know what I would do, I really don't know. If it were a serious disease, I would treat it for sure. If someone comes just because they have [...] a cold, I would possibly tell them... I don't know (benA09).

The deontological code, institutional logic and expert knowledge that underlie and justify a doctor's discretion are essentially the same whether s/he works in Barcelona or London. The somewhat tighter rules that the UK government has put in place, however, can make it more difficult for healthcare professionals to 'sort out' individual cases, as the following statements of a nurse (1) and a GP (2) I interviewed in London indicate:

(1) There is a little loophole because anything that is urgent or immediately necessary is free at the point of delivery. So, if there are patients [in an irregular situation] and it is kind of life threatening or critical... so if you can argue that without an intervention, they will be even more unwell, then that's a loophole. But obviously not everything can be argued like that, and it depends which healthcare provider you are arguing with (lonA13).

(2) I mean I personally would like to... to do that... I mean, I'd probably try and help patients to get [the treatment they need], even though sometimes they are not eligible, so it's probably not right... but... it's difficult. I think it's sometimes the right thing to do [if] it's in the best interest of the patient (lonA25).

In addition, and closely related to individual discretion, the medical profession also brings with it a significant degree of responsibility for the wellbeing of the patient, so that doctors in particular - even if personally they were 'against immigration' - could not simply choose to ignore their duty of care without potentially "risking their career", as several of my interviewees explicitly emphasised (bcnA08, lonA08, lonA11). Arguably, it is precisely because the nature of their job forces them "to attend to the persons and not to their administrative status" (bcnA10) - as a community health worker in Barcelona put it - that medical professionals usually tend to be shielded from having to perform gatekeeping functions that are not based on medical necessity but administrative criteria like local residence, income or immigration status. In both cities, several professionals and NGO workers I interviewed assured me that

doctors and nurses themselves don't put up barriers. [...] I am speaking as a nurse myself and having lots of medical colleagues I don't think we see a problem with our patients being from abroad or with our patients not having papers. We see a patient from the point of view that they are sick and unwell, and they need our medical help. I think the problem comes in the people before they see the doctor or nurse (lonA13).

The UK Department of Health (2010, p. 27), however, also recognised "the crucial role that GPs already play in committing NHS resources through their daily 
clinical decisions - not only in terms of referrals and prescribing, but also how well they manage long-term conditions, and the accessibility of their services" (emphasis added). Behind what appears to reflect purely economic considerations lies a clear tendency of healthcare staff increasingly being expected to (help) police the government's immigration rules, which at the same time are becoming ever more restrictive and complex. Especially GPs (as well as certain A\&E staff) could according to official guidelines - systematically "identify in the referral letter any patient whom they believe may be an overseas visitor, which the relevant NHS body could then check" (Department of Health, 2013a, p. 52). Individual doctors are thereby increasingly put in a difficult position, as a GP in London pointed out to me:

If that happens - because there has been also talk about that we should be one of the first... well... to put barriers, and we should actually identify people - it can be difficult with confidentiality. If for example, someone comes in and they are an 'illegal' immigrant and I see them as an emergency and they say, 'oh please don't say I am [irregular]', then this is... I don't know what to do in that situation. I wouldn't know (lonA25).

But even without this 'suggestion' having yet become a formal obligation for doctors and nurses, the same interviewee later also acknowledged that already now she sometimes considers that the best advice she can give to a foreign patient is to leave the UK:

I mean, of course, if it is an emergency, they will get the help, but if someone needs continuous treatment $[\ldots]$ and it's sometimes something that takes years... so I mean, we have to give the patient the best advice, and sometimes really the best advice is actually not to be here if they have a difficult situation... because that means that they cannot get... the care would not be continuous, it would not be very effective (lonA25).

Arguably, her account suggests that she not only considers advising certain patients to better leave the UK 'voluntarily', but that she also anticipates their likely deportation in case they do not - which is what in fact would then disrupt the treatment. Even without being legally obliged to do so, she thereby already assumes her designated role for the immigration regime and almost seems to have accepted her place within the 'hostile environment' through which the government aims at precisely that: encouraging return. This is a good example of how welfare workers can effectively become migration managers and return thereby an obvious solution to migrant irregularity. It also shows how the negative media and public discourse whether focused on 'health tourism' or the imperative to 'fight illegal immigration' more generally - actually undermine not only the patients' legal entitlements but also individual doctors' duty of care (DOTW, 2013). All of this puts in jeopardy the confidentiality and trust that is not only essential to the doctor-patient relationship but also necessary for a correct diagnosis and successful treatment (Kilner, 2014; Wind-Cowie \& Wood, 2014).

As will become clear from my analysis, also hospital doctors are increasingly expected to at least consider the immigration status of foreign patients when assessing their medical needs. The following quote of a nurse working in the A\&E department of a hospital in North-London highlights the underlying contradiction: 
[The patient's immigration status] shouldn't make a difference. It would not be ethical if it did make a difference to the [doctor's] decision [of which treatment is 'urgent']. Because they should be seeing the patient solely based on what is wrong with the patient, not on whether or not the patient is entitled to free healthcare (lonA13).

The UK government is aware of the inherent problem and noted that "[c]linicians are not expected to take on the role of immigration officials, but they are often well placed to identify visitors who are chargeable" (Department of Health, 2013b, p. 17). However, as long as immigration status is the main criterion for charging someone, and NHS staff - even if not necessarily clinicians themselves - have to identify who is chargeable, they will effectively be playing a role in controlling immigration. Importantly, this is not just a question of ethics, but also of correspondence between the allocation of competences and adequate training, as the GP I quoted above also emphasised:

I mean people will have different opinions [but] I personally don't think that as healthcare workers that is our job. We are not... I don't feel we should be border control. [...] I think this kind of checking and border control should be done by other people and not by healthcare workers. Public health shouldn't be involved in it. Sometimes it is very difficult for us as healthcare workers to ascertain that someone is an illegal immigrant, $[\ldots]$ because it's not something that we are trained to do (lonA25).

What she refers to is primarily the checking of relevant documents in order to establish someone's immigration status, or what I called 'having to know' when I introduced my analytical framework in Chap. 2. But also the second dimension of this framework and of being implicated in immigration control - 'having to tell' has an impact on how individual healthcare workers interact with their patients, and vice versa. The A\&E nurse I interviewed in London put it like this:

If doctors or nurses have to disclose the status of their patients all the time, it will be affecting the treatment that they give them, and nothing should affect the treatment that you are getting from a doctor or a nurse. [...] It will affect [it] because the patient would not engage as much with the services if they are thinking 'oh, the Home Office is going to find out', or 'I will need to pay'. It's going to be too stressful; they are not [even] going to come to a doctor or nurse (lonA13).

Given the sensitivity of the personal data that healthcare staff in general and professionals in particular are handling in their everyday work, confidentiality and data protection requirements play an important role in the area of healthcare and constitute a crucial element of individuals' professional duty. While several of my respondents in both cities were not sure whether or not there was a specific law or regulation that explicitly prohibits passing immigration related information about their patients to other agencies, almost all of them - and doctors in particular - made very clear that they would never do so:

I think doctors will consider it as just another issue of professional secrecy. It's the same as if someone tells you that $\mathrm{s} /$ he maintains high-risk sexual relationships or anything like that... and so, well, it's a secret. I don't know how this would be considered from an administrative point of view, but... [...] I think that as doctors we don't consider ourselves to be the police for anything; but actually the contrary, in this sense (bcnA09). 
This last statement of a family doctor I spoke to in Barcelona strikingly coincides with the following - made by a GP in London - in that both make a similar distinction between doctors on one hand and administrative staff on the other.

[...] The General Medical Council [GMC] rule states that I may not even disclose that a patient is registered here, [...nor] any information whatsoever, without their consent. Now that applies to doctors. But our managers here would not do it either; and our receptionists obviously know not to give information to anybody over the phone. [...] But once somebody from the Home Office did phone our manager and said 'well, we need this information', and she said 'well, I am quoting you the GMC rule', and he or she said back 'oh... but some doctors choose to give this information', which was fairly horrifying, that apparently some doctors are... Now, they may be doing it in an innocent way, or they may not even realise (lonA11).

Whereas professional providers and administrators of mainstream public healthcare often rather inadvertently come to play a certain role within the overall management of migration, both the British and Catalan cases demonstrate that the internalisation of control also creates the need for new institutional structures and personnel that specifically deals with migrant irregularity within the healthcare system.

\subsection{3 'Managers' of Irregularity Within the Healthcare System}

The UK Department of Health (2013b, p. 13) emphasises that all "[r]esidency based, tax-funded systems rely on the identification of those who are not entitled rather than those who are, with the onus on staff to identify those who should be charged." While this leaves open at which stage, by whom, and on what basis such identification should be carried out, it is pertinent not only to the UK context but also for the Catalan health system. At the same time, an important difference becomes apparent here: Whereas in the case of Catalonia the level of any particular patient's entitlement (depending on income, employment status and length of residence) is clearly indicated on their personal health card, 'Overseas Visitors' in the UK, once they are registered with a GP, hold exactly the same kind of NHS card as any other patient. This lack of specification of the holder's entitlement beyond primary and emergency care is a remainder of the system's universalistic origins and makes it difficult for hospitals to comply with the legal obligation that is now placed directly on them, "to determine whether the Charging Regulations apply to any overseas visitor they treat" (Department of Health, 2013a, p. 16).

At the hospital level, this mismatch has created the need for a particular kind of administrative personnel - that is, a new organisational role - responsible for identifying who is chargeable. It is not surprising that from the perspective of these so-called Overseas Visitors Managers (OVMs) one of the major problems of the NHS is that people too easily 'slip through the system', as the OVM of a mid-sized hospital in South-East London explained to me: 
$[\ldots]$ and the reason why they can slip through the system [...] is that anybody can obtain a national health number. [...] All they do, actually, is go to a GP, ask the GP to register them, and the GP registers them and gives them an NHS number (lonA09).

On one hand, this reflects what according to one of the GPs I interviewed has become a common view within the NHS: that GP registration itself constitutes "an underground route to secondary care" (lonA11). On the other hand, the OVM acknowledged that even though "by law, we have to check every new patient that comes into the hospital, [...] that is physically impossible, and it would cost an absolute fortune" (lonA09); which is why in practice her department focuses mainly on the areas of women's health and orthopaedic. Asked for the reasons behind this selection, she explained that it was "principally because a lot of people come over here to give birth, and orthopaedic because it is quite an expensive area", but she also mentioned that "we have also good staff that we could encourage to participate in those sections" (lonA09). The exact meaning of this comment only became clear to me when she later received a phone call from the hospital's maternity ward notifying her about the arrival of a new patient, after which she explained to me:

In that case I would be very very surprised if that person is entitled to NHS care. So, we will go up to see her, we will ask her to see her documentation. I mean she is on the labour ward, so I don't think that's the right time to ask, personally, so I will probably leave that and go after she has given birth. We will ask to see her documentation; we will ask her relatives to bring in that documentation. It could be that she has got leave to remain. It may have been that she just came to see her family and just came down... you know, we cannot guarantee it but that case we would class as suspicious (lonA09).

Her account is a good example of how "NHS staff often have to make assumptions about government [immigration] policy in their work", as Wind-Cowie and Wood (2014, p. 55) have noted; but it also highlights the level of direct implication of her role in the actual enforcement of this policy, as well as the very subtle kind of discretion (as to whom, when and how to check) that she thereby employs. Asked what happens in case a patient is not able to prove their entitlement, or even to produce a valid passport, my interviewee replied that

they have to produce their passport, which [...] will have a stamp in it, so that will show whether that person is entitled or not. From there, once we have identified her, we will raise an invoice. If she doesn't pay... again: we have to treat this patient, but if she doesn't pay, then in three months' time that invoice will be going over to... we will inform the Department of Health [...] who then filter it and would let the Home Office know (lonA09).

Interestingly, while she clearly perceived her role within the hospital and the NHS as one of control, she did not readily acknowledge that what she is controlling is immigration. Instead, when I asked her how she felt about 'quasi' acting as an immigration officer, her answer was rather ambiguous:

I don't think we do. I mean, if you were an immigration officer you would be informing immigration [authorities], you would be informing the borders agency. And we will work with the border agency, and we will let the... Department of Health know of patients that owe us money... Now: it's the Department of Health that then would possibly pass that information to the Home Office, and it would, you know, then put it on a system so that perhaps these people... but they are not traced here! It's normally the people that try to get 
back [into the UK] that we are stopping. [...] So personally, I don't think that we work as an immigration officer... maybe wrongly, perhaps we do (lonA09).

She clearly emphasised that she and her team are not targeting immigration offenders but patients who owe the hospital money. At the same time, however, she is aware that her role - together with the mechanism that 'lets the Home Office know' - plays a decisive part in the government's broader efforts to limit irregular residence, but also unwanted immigration more generally:

I believe that that is a deterrent, and I think what it is doing is stopping a lot of people getting their Leave to Remain. What we are also finding is that some of the patients that have gone home, wherever that might be... the Caribbean, Africa, Asia... you know; they have gone home with a debt but when they apply for another visa, they are being told that they can't get it (lonA09).

Such outstanding NHS debt can thereby function as an effective barrier to regularisation, even where an applicant would otherwise meet the legal requirements. Importantly, the connection between healthcare and immigration control also works the other way around, so that even doctors are increasingly expected to take their patients' immigration situation into account when assessing their medical needs. When I asked the OVM whether the hospital doctors were aware of these regulations, she said:

Well, they don't need to know [the regulations], do they? We will send them a letter saying that their patient has been identified as not entitled to NHS treatment, and that we would therefore like to get confirmation from them as to how they wish to proceed.

[Interviewer] So a patient having or not having LTR could influence their assessment? Yes, it will. It has got to (lonA09).

While the immigration status of a patient is explicitly not supposed to influence the assessment of a doctor working in the Catalan healthcare system, also this system relies on certain ways to identify patients who should (and can) be charged for the treatment they receive, whether directly or via their insurance if they have one. In principle, this happens at the level of CatSalut, where the patient information recorded by health centre receptionists is centralised and screened for potential fraud, as a community health worker explained to me:

Once CatSalut receives the documents of the person, there is an additional filter. That's where they investigate whether this person is a tourist who comes to take advantage of the health system or is a person without resources. [...] So not everyone who has applied for a health card has also been granted one. Not everyone. Because they saw that there are [some] persons who are not in this situation of vulnerability. But others, however, really need it because they are in an extreme situation. So, they [CatSalut] evaluate this quite well, I think (bcnA02).

CatSalut thus generally tries to draw a line between residents who (mostly because of their immigration status) are excluded from the national insurance system but also unable to pay privately, and non-residents suspected of 'health tourism'. For the UK system, in contrast, both of them are 'Overseas Visitors' and thus automatically placed in the same administrative category, which not only blurs two very distinct social realities (Wind-Cowie \& Wood, 2014) but also renders even 
those entitlements that irregular migrants theoretically have less visible (Schweitzer, 2019).

In Catalonia, as mentioned in Sect. 5.2, those relatively few cases of patients who were identified as entitled to free primary but not (yet) secondary care had to be managed individually by a special commission within CatSalut, as the organisation's client relations manager explained to me in May 2015, less than 2 months before the access rules were simplified and the commission dissolved:

The so-called Commission of Exceptional Access to Programmed Specialised Care was created to deal with those cases that did not have access to specialised care but because of their illness had to be treated; and [of those] we have had 60 or 70 cases a year... that is, there are very few people who are asking us [...] to be treated or admitted to a hospital during that first year. [...]

[Interviewer] And what is the decision of this commission based on, then?

The decision is based on a clinical report issued by a hospital, saying 'this person with this diagnosis would have to be provided access to specialised care'. And so, there is this commission formed by a lawyer, a purchasing specialist, a hospital doctor, a member of the Client Relations Department, and there is also a pharmacist... and between these professionals they analyse the case and then say yes or no. Basically in all the cases presented - I think 99 per cent - they said yes (bcnA17).

In accordance with this account, one of the health centre administrators I interviewed in Barcelona remembered "only one or two non-urgent cases" where patients had to wait until they fulfilled the 1-year residence requirement (bcnA08), whereas in all other cases they did receive the treatment that the family doctor had deemed necessary. In practice, the administrative categorisation and corresponding levels of eligibility that had been put in place in order to at least temporarily limit irregular migrants' access to secondary public healthcare had thus routinely been overruled by professional assessments of what the patient's medical condition required to be done. The responsibility and power to manage this particular aspect of irregularity has thereby remained in the hands of local actors primarily committed to the logic of providing healthcare (and shielded from that of immigration control), which stands in stark contrast to the role and duties of Overseas Visitors Managers in the UK context.

Another kind of actors, which are often crucial for the management of irregularities that public welfare systems face are NGOs and private associations. Their functions range from information, awareness raising and advocacy to the actual provision of complementary or even alternative services to particularly vulnerable groups. Their relationship to mainstream services can thereby be more or less formalised. In Catalonia, for example, they have become responsible for supporting the registration of those patients who cannot provide the otherwise necessary documentation, as the administrator of a CAP explained to me:

Before, those who came without anything, without papers, were handled here. There was an application form for all those who came without papers and we processed them here. But with the new law this group has been diverted to associations that are dedicated to doing just that.

[Interviewer] So the law itself establishes that these associations have this role? 
Well, it has been agreed between CatSalut and these associations. The instruction [10/2012] simply says that these people without papers will be attended; that's what CatSalut says [...] but the procedure of how we apply this is now that these associations are doing it (bcnA08).

It is important to emphasise that here 'without papers' refers to the lack of a patients means of identification, not the 'illegality' of his or her residence, which per se does not hinder their inclusion into the mainstream system, as the same interviewee later clarified:

For me, the undocumented are those who come by boat ['en patera'] with what they have on them, with no identification or anything, and these come through the associations. But those who came by plane [i.e. on a tourist visa, which they overstay] and have a passport... I can attend them and process their application without any problem (bcnA08).

More specifically, in 2015 CatSalut signed an agreement with the Red Cross, which empowers the organisation to certify - in cases of exceptional vulnerability and for the sole purpose of issuing a health card - that someone is residing within a municipality of Catalonia even though s/he is not officially registered ( $\mathrm{La}$ Vanguardia, 2015). For CatSalut's client relations manager, this was a step that "has helped us to close that little gap that had been left unresolved [by the law], because obviously it was not the fault of these persons that in some municipalities, they wouldn't allow them to register [without official proof of address, for example]" (bcnA17). Several of my interviewees have noted that without the help of a friend or support group, many migrants in irregular situations would not be receiving the care they are entitled to. In some cases, this facilitation works through personal contacts that NGOs have established with individual doctors (or reception staff), as the experience of a 19-year-old migrant from Gambia demonstrates:

When I didn't have my health card, in the flat where I was staying they [the NGO which provided the flat] had some contact with a doctor at [a particular CAP], and so I went there to do an analysis [...] and it was before I had the three months of local registration. [Interviewer] So, it is known that [this CAP] is a place where you can go even without a health card?

Well, you cannot go alone. Alone not, my [social worker] took me there but if I would have gone alone... no. If someone is with you or anyone has any contact, then they can call and [...it will work] (bcnB02).

Of the many charitable, community and migrant organisations and initiatives that are active (and usually based) in London, one particularly stands out in the area of health: Doctors of the World (DOTW) UK has for many years been operating a dropin clinic in East-London (run by volunteer doctors and nurses), an advice line for people experiencing difficulties registering with GPs, and a nation-wide advocacy programme dedicated to the promotion of equal rights to healthcare. Since December 2014, DOTW is also running a second clinic in Hackney, which was commissioned and funded (initially as a 6-month pilot scheme) by the City \& Hackney Clinical Commissioning Group (CCG). In a press release the local NHS body confirmed that "Doctors of the World received $£ 50,000$ to provide support and advocacy for patients in vulnerable situations in Hackney, making sure they are able to register with a GP and overcome other barriers to healthcare" (City \& Hackney CCG, 2015). What it 
did not mention is that for roughly $70 \%$ of the persons that DOTW receive - including many pregnant women and other medically urgent cases - the barrier is their immigration status.

In practice it can often only be overcome by volunteers doing "a lot of work to persuade people that [going to a doctor] is the right thing to do and that it's safe, or at least likely to be safe", as the organisation's programme director told me (lonA03). The volunteers I interviewed did not perceive this work as a political act or even statement, because "the law says that they can be linked in with a GP, so we are just... I don't want to say enforcing the law... but we are kind of just taking what's already laid out and just applying it" (lonA12). Also here, the aim is thus not to set up a parallel system for a certain group of people but to direct them to mainstream care, which according to one nurse who regularly volunteers for DOTW often requires individual solutions, since

barely any of the patients we see in this clinic have photographic identification [...], but doctors' surgeries normally need that [...]. So, we do a lot of negotiating here and a lot of trying to provide letters for proof of identification and address, and some GPs accept that and are very kind, and others make a bit of a fuss (lonA13).

Her experience reflects an important difference between the two environments in terms of how Third Sector organisations relate to and collaborate with mainstream services even though in both contexts they fulfil a similar function. Whereas in Catalonia their mediating role has largely been formalised through official agreements, in the UK it seems to work in a rather ad-hoc manner and thus again hinges on the willingness of individual healthcare staff to accept it.

The empirical data I presented so far allows to draw some general conclusions: firstly, the nature of public healthcare inevitably leaves significant scope for individual discretion; secondly, every patient is automatically subjected to such discretion, which can have exclusionary as well as inclusionary effects; and thirdly, this discretion becomes problematic where it is not just based on medical indications but also the (il)legality of the patients' residence in a given state. In the final section of this chapter, I will summarise my findings and visualise the various positions that different kinds of healthcare workers in London and Barcelona occupy in relation to the respective immigration regimes.

\subsection{Healthcare Workers as Migration Managers?}

The initial idea behind the framework I have developed for my analysis of the micro-management of irregular migration and its control was that individual actors and the roles they play within a particular organisational field could be differentiated and compared according to their specific position in relation to the immigration regime. One of the aims was to thereby visualise the different kinds of their being or becoming implicated in immigration control and/or enforcement efforts. 
Figure 5.2 shows the results of this exercise for the area of healthcare, based on the empirical findings presented in this chapter.

Each of the six rectangles represents one of the three role-categories - administrators, (medical) professionals and managers of irregularity - for one of the two environments. This enables comparison between different kinds of roles in the same context as well as similar roles across contexts. Their position across the 16 subsectors of the diagram indicates the degree or likelihood of them being involved in immigration control - on a scale ranging from deputisation, via responsibilisation and autonomisation, to shielding. Their position along the horizontal axis thus shows whether they are formally required or explicitly encouraged to know and thus somehow check the immigration status of a patient (left side of the framework), or effectively prevented from doing so (far right). Accordingly, their position along the vertical axis indicates their deputisation, responsibilisation, (potential) autonomisation, or shielding in relation to the question of whether or not to tell the immigration authorities in case they detect (or suspect) irregularity. Their relative position to each other reflects minor variations in terms of how concrete and compelling these rules or expectations are in everyday practice, according to the perceptions and reported experiences of my interviewees.

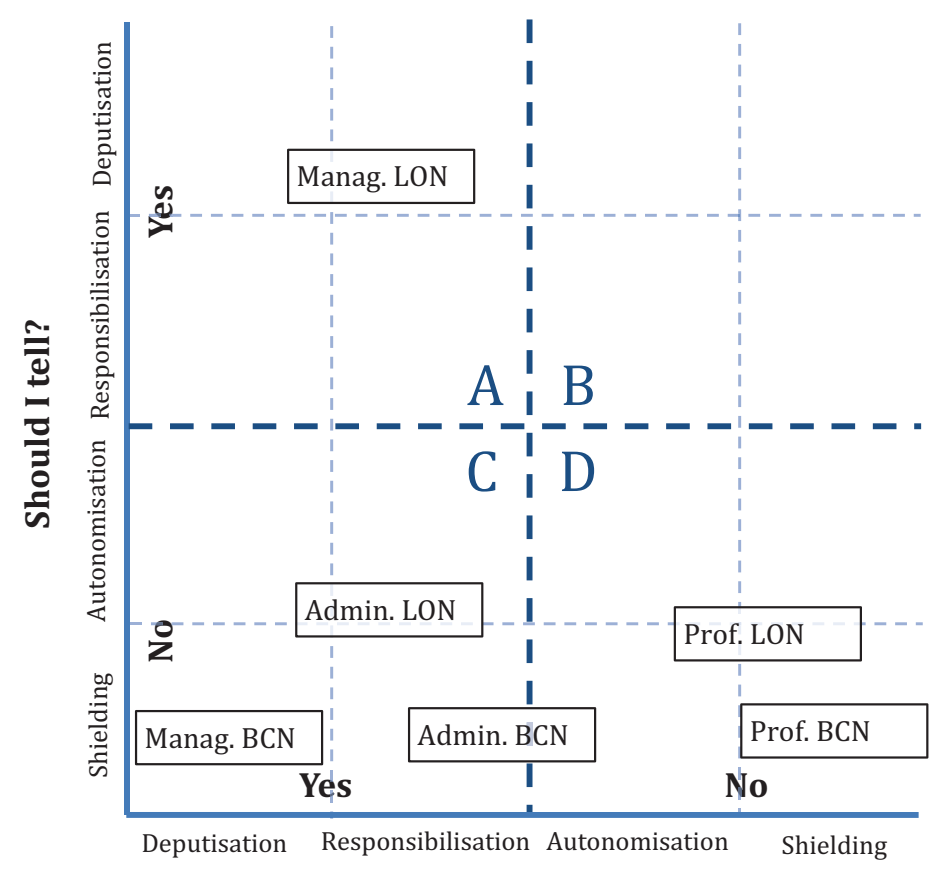

Should I know?

Fig. 5.2 The positions of different categories of healthcare workers in relation to migrant irregularity and its control 
Both in London and Barcelona, administrators of healthcare are generally expected to (at least try to) find out the immigration status of a patient who wants to register. Although it is not their primary role to systematically check passports, they often rely on such documents to establish a patient's identity and/or eligibility. Since they are not obliged nor explicitly encouraged to share any of the information they thereby obtain (potentially including a patient's irregular immigration status) with the relevant authority, they are placed in sector ' $\mathrm{C}$ ' of the framework. That those in Barcelona appear further to the right reflects two aspects: their stronger awareness that they cannot actually be expected to 'force' patients to prove their immigration status; and that regular status is less likely to be perceived as a precondition for registration with the Catalan healthcare system. Those in London are also closer to the top since they seem more likely to consider sharing immigration related information with the responsible authority, which explains the widespread (and not completely unfounded) fear among irregular migrants that dealing with healthcare administrators might trigger immigration enforcement.

Healthcare professionals working in London and Barcelona share the same 'deontological code' and values, and thus a strong conviction that immigration control is not part of their job. They are generally shielded from most gatekeeping functions and are not expected to check the eligibility or documentation of their patients themselves. Their work requires higher standards of confidentiality and data protection, which explicitly prohibit them to pass any personal information of their patients to other agencies, unless they have the patient's consent. In neither of the two cities are they formally obliged to know the immigration status of their patients, or to tell the relevant authorities if they happen to discover their irregularity. They are thus both placed in sector ' $\mathrm{D}$ ', whereby professionals in London are somewhat closer to sector ' $\mathrm{C}$ ' - since they sometimes do take immigration status into account when deciding which kind of treatment to offer; and closer to sector 'B' - because they are less explicitly shielded from, and in fact seem more likely to feel compelled to, share such information with the relevant authorities.

In both environments a certain management of irregularity becomes necessary because of how the rules and the systems for their implementation are set up, which creates the need for specific personnel. These managers of irregularity are (per definition) concerned with the immigration situation of the people whose cases they deal with, which is why they appear on the left side of the diagram. In Barcelona, the special commission that used to manage irregular migrants' exceptional access to secondary care was not linked to the immigration authority and its decisions were primarily based on a medical assessment of the patient's situation rather than their immigration status. Overseas Visitors Managers in London, in contrast, also work within the healthcare system but very much according to the logic of immigration control. While officially committed to the recovery of NHS debt, their main activity is checking immigration statuses - although they are not obliged by central government to check each and every patient. What arguably (and against my interviewee's self-perception) puts them close to the top of the diagram, however, is the mechanism through which the knowledge of patients' outstanding debt as well as their unlawful presence in the country is shared with the Home Office. For a 
health advocate I interviewed in London, this "changes everything, because it's the way that they have now discovered to penalise" (lonA08).

Crucial for my analysis is that the underlying policy not only aims at disciplining irregular migrants themselves but also the individual street-level bureaucrats through which the state delivers its services. Seen from this perspective, it is not a coincidence that healthcare workers in London increasingly feel under pressure to participate in the management of migration, as the A\&E nurse told me:

Well at the hospital I don't ask my patients anything to do with their immigration status, because if you [find out], the hospital unfortunately will have to act on it, and you will have to let your senior know and to let the hospital manager know [...]. So, it is very difficult in a hospital if you have that knowledge and someone knows you have that knowledge and then you don't pass it on, you know... I get in trouble [...] So I tend to not ask my patients because I don't want to... I do not want to know (lonA13).

On one hand, her statement reveals her concern about potentially being 'penalised' herself for failing to disclose her knowledge about the 'illegality' of a patient's residence in the UK. On the other hand, she also hints at one way of avoiding such punishment: refusing to know, which generally appears to be an important mode of resistance against the internalisation of immigration control. As I will discuss at the beginning of the next chapter, the possibility of refusing to know has also been at the centre of a heated debate about whether or not British schools should collect information of their pupils' country of birth and nationality.

\section{References}

Aasen, H. S., Kjellevold, A., \& Stephens, P. (2014). 'Undocumented' migrants' access to health care services in Europe: Tensions between international human rights, national law and professional ethics. In H. S. Aasen et al. (Eds.), Juridification and social citizenship in the welfare state (pp. 162-182). Edward Elgar Publishing, Incorporated.

Agència de Salut Pública de Barcelona. (2011). Immigració $i$ serveis sanitaris a la ciutat de Barcelona. La perspectiva de la població marroquina, xinesa, equatoriana i pakistanesa. Barcelona.

Ajuntament de Barcelona. (2013). Documento informativo sobre: Nueva directiva para el acceso al sistema púnblico de salud. Barcelona.

Aspinall, P. (2014). Inclusive practice. Vulnerable migrants, gypsies and travellers, people who are homeless, and sex workers: A review and synthesis of interventions/service models that improve access to primary care \& reduce risk of avoidable admission to hospital. Available at: https://www.gov.uk/government/uploads/system/uploads/attachment_data/file/305912/ Inclusive_Practice.pdf

Ball, J. (2014). Home Office accessing NHS records to help track down illegal immigrants. The Guardian. Available at: http://www.theguardian.com/uk-news/2014/jul/13/home-office-nhsrecords-illegal-immigrants. Accessed 10 May 2016.

Blay, B. (2015). El Govern abre las puertas de la sanidad pública a colectivos que quedaban excluídos. El Diario. Available at: http://www.eldiario.es/catalunya/diarisanitat/Govern-sanidadcolectivos-quedaban-excluidos_6_412318790.html. Accessed 10 May 2016. 
BMA. (2013). Guidance for GP practices: Overseas visitors and primary care. British Medical Association. Available at: http://www.blmc.co.uk/docs/BMA - Overseas Visitors and Primary Care _ British Medical Association.pdf.

Boswell, C. (2007). Theorizing migration policy: Is there a third way? International Migration Review, 41(1), 75-100. https://doi.org/10.1111/j.1747-7379.2007.00057.x

Cebulko, K. (2018). Privilege without papers: Intersecting inequalities among 1.5-generation Brazilians in Massachusetts. Ethnicities, 18(2), 225-241. https://doi. org/10.1177/1468796817752562

City \& Hackney CCG. (2015). £400k fund launched for local health projects.

da Lomba, S. (2011). Irregular migrants and the human right to health care: A case-study of healthcare provision for irregular migrants in France and the UK. International Journal of Law in Context, 7(3), 357-374. https://doi.org/10.1017/S1744552311000188

Delvino, N. (2020). European Union and national responses to migrants with irregular status: Is the fortress slowly crumbling? In S. Spencer \& A. Triandafyllidou (Eds.), Migrants with irregular status in Europe. Evolving conceptual and policy challenges (pp. 73-97). Springer. https://doi.org/10.1007/978-3-030-34324-8_5

Department of Health. (2010). Equity and excellence: Liberating the NHS.

Department of Health. (2012). 2012 review of overseas visitors vharging policy. Available at: https://www.gov.uk/government/uploads/system/uploads/attachment_data/file/210439/ Overseas_Visitors_Charging_Review_2012_-_Summary_document.pdf

Department of Health. (2013a). Guidance on implementing the overseas visitors hospital charging regulations. Available at: https://www.gov.uk/government/publications/ guidance-on-overseas-visitors-hospital-charging-regulations

Department of Health. (2013b). Sustaining services, ensuring fairness. A consultation on migrant access and their financial contribution to NHS provision in England.

DOTW. (2013). Access to Healthcare in Europe in times of crisis and rising xenophobia.

DOTW. (2016). Registration refused: A study on access to GP registration in England. London. Available at: https://www.doctorsoftheworld.org.uk/files/RegistrationRefusedReport_MarOct2015.pdf

Feldman, R. (2020). NHS charging for maternity care in England: Its impact on migrant women. Critical Social Policy. https://doi.org/10.1177/0261018320950168

FRA. (2013). Apprehension of migrants in an irregular situation - Fundamental rights considerations.

FRA. (2015). Cost of exclusion from healthcare - The case of migrants in an irregular situation. Available at: http://fra.europa.eu/en/publication/2015/cost-exclusion-healthcare-casemigrants-irregular-situation. Accessed 5 Oct 2015.

Hall, M. A., \& Perrin, J. (2015). Irregular migrant access to care: Mapping public policy rationales. Public Health Ethics, 8(2), 130-138. https://doi.org/10.1093/phe/phv016

Hermansson, L., et al. (2020). Firewalls: A necessary tool to enable social rights for undocumented migrants in social work. International Social Work. https://doi.org/10.1177/0020872820924454

Home Office. (2013). Immigration bill factsheet: Overview of the bill. Available at: https:// www.gov.uk/government/uploads/system/uploads/attachment_data/file/249251/Overview_ Immigration_Bill_Factsheet.pdf. Accessed 5 Apr 2017.

Isin, E. F. (2008). Theorizing acts of citizenship. In E. F. Isin \& G. M. Nielsen (Eds.), Acts of citizenship (pp. 15-43). https://doi.org/10.1016/B978-0-7020-2797-0.00001-1

Johnson, W. (2012). Boris Johnson criticised over medical guide for migrants. The Independent, 11 April. Available at: http://www.independent.co.uk/news/uk/politics/boris-johnson-criticisedover-medical-guide-for-migrants-7636287.html. Accessed 10 May 2016.

Kilner, H. (2014). Hostile health care: Why charging migrants will harm the most vulnerable. The British Journal of General Practice, 64(626), e590-e592. https://doi.org/10.3399/ bjgp14X681565

Kirkup, J., \& Winnett, R. (2012). Theresa May interview: "We're going to give illegal migrants a really hostile reception". The Telegraph. Available at: http://www.telegraph.co.uk/news/ uknews/immigration/9291483/Theresa-May-interview-Were-going-to-give-illegal-migrantsa-really-hostile-reception.html. Accessed 9 Nov 2015. 
Kraler, A. (2011). Fixing, adjusting, regulating, protecting human rights - The shifting uses of regularisations in the European Union. European Journal of Migration and Law, 13, 297-316.

La Vanguardia. (2015). Cruz Roja y Salud garantizarán el acceso a la sanidad a personas vulnerables. Available at: http://www.lavanguardia.com/vida/20150302/54427822808/cruzroja-y-salud-garantizaran-el-acceso-a-la-sanidad-a-personas-vulnerables.html. Accessed 27 Nov 2017.

Legido-Quigley, H., et al. (2013). Erosion of universal health coverage in Spain. The Lancet, 382(9909), 1977. https://doi.org/10.1016/S0140-6736(13)62649-5

Lipsky, M. (1987). Street-level bureaucrats as policy makers. In D. L. Yarwood (Ed.), Public administration, politics, and the people: Selected readings for managers, employees, and citizens (pp. 121-127). Longman.

MdM. (2014). Dos años de reforma sanitaria: más vidas humanas en riesgo. Available at: http://www.medicosdelmundo.org/index.php/mod.documentos/mem.descargar/fichero. documentos_Impacto-Reforma-Sanitaria-Medicos-del-Mundo_3ec0bdf9\%232E\%23pdf

N.d. (2015). El Gobierno anuncia que devolverá parte de la atención sanitaria a los inmigrantes sin papeles. El Diario. Available at: http://www.eldiario.es/sociedad/inmigrantes-irregularesvolveran-atencion-primaria_0_372362835.html

OHCHR. (2014). The economic, social and cultural rights of migrants in an irregular situation. New York/Geneva.

PASUCAT. (2014). Dos anys des del canvi de model sanitari. Dos anys d'exclusió. Available at: https://docs.google.com/file/d/0B2opi6SzvyEKTXRxTWtLTjIxNmc/edit

PICUM. (2009). Undocumented and seriously Ill: Residence permits for medical reasons in Europe. Available at: http://picum.org/picum.org/uploads/publication/Undocumented_and_ Seriously_Ill_Report_Picum.pdf

Rejón, R. (2015). El Gobierno crea un documento especial para que los inmigrantes sin papeles vayan al médico. El Diario. Available at: http://www.eldiario.es/sociedad/Gobierno-volveraninmigrantes-Atencion-Primaria_0_372362938.html. Accessed 27 Nov 2017.

Romero, M. (2008). The inclusion of citizenship status in intersectionality: What immigration raids tells us about mixed-status families, the state and assimilation. International Journal of Sociology of the Family, 34(2), 131-152. Available at: http://www.jstor.org/ stable/10.2307/23070749

Schrover, M., \& Schinkel, W. (2013). Introduction: The language of inclusion and exclusion in the context of immigration and integration. Ethnic and Racial Studies, 36(7), 1123-1141. https:// doi.org/10.1080/01419870.2013.783711

Schweitzer, R. (2017). Integration against the state: Irregular migrants' agency between deportation and regularisation in the United Kingdom. Politics, 37(3), 317-331. https://doi. org/10.1177/0263395716677759

Schweitzer, R. (2019). Health care versus border care: Justification and hypocrisy in the multilevel negotiation of irregular migrants' access to fundamental rights and services. Journal of Immigrant \& Refugee Studies, 17(1), 61-76. https://doi.org/10.1080/15562948.2018.1489088

Scott, W. R. (2001). Institutions and organizations. SAGE Publications.

semFYC. (2012). Analysis ético ante la retirada de la asistencia sanitaria a inmigrantes sin permiso de residencia. Available at: http://www.semfyc.es/pfw_files/cma/noticias/noticia/analisis_etico_retirada_asistencia_sanitaria.pdf

Steele, S., et al. (2014). The Immigration Bill: Extending charging regimes and scapegoating the vulnerable will pose risks to public health. Journal of the Royal Society of Medicine, 107(4), 132-133. https://doi.org/10.1177/0141076814526132

Vosyliute, L., \& Joki, A. -L. (2018). Integration. The social inclusion of undocumented migrants. ReSOMA.

Webb, J. (2006). Organisations, identities and the self. Palgrave Macmillan.

Wind-Cowie, M., \& Wood, C. (2014). Do no Harm. Ensuring fair use of the NHS efficiently and effectively. London. Available at: http://demos.co.uk/files/Demos_DoNoHarmREPORT. pdf?1413823102 
Open Access This chapter is licensed under the terms of the Creative Commons Attribution 4.0 International License (http://creativecommons.org/licenses/by/4.0/), which permits use, sharing, adaptation, distribution and reproduction in any medium or format, as long as you give appropriate credit to the original author(s) and the source, provide a link to the Creative Commons license and indicate if changes were made.

The images or other third party material in this chapter are included in the chapter's Creative Commons license, unless indicated otherwise in a credit line to the material. If material is not included in the chapter's Creative Commons license and your intended use is not permitted by statutory regulation or exceeds the permitted use, you will need to obtain permission directly from the copyright holder. 